\title{
COVID-19 NA REGIÃO DE SAÚDE TRIÂNGULO SUL, MG: UMA PERSPECTIVA CARTOGRÁFICA
}

\section{COVID-19 IN THE TRIÂNGULO SUL HEALTH REGION, MG: A CARTOGRAPHIC PERSPECTIVE}

\author{
Ricardo Vicente Ferreira \\ Universidade Federal do Triângulo Mineiro - UFTM, Campus Uberaba \\ ricardo.ferreira@uftm.edu.br \\ Denise Maciel Carvalho \\ Secretaria de Estado de Saúde de Minas Gerais/SRS/Uberaba \\ denise.carvalho@saude.mg.gov.br \\ Ana Laura de Paula Souza \\ Universidade Federal do Triângulo Mineiro - UFTM, Campus Uberaba \\ analauradepaulasouza@gmail.com \\ Marcos Roberto Martines \\ Universidade Federal de São Carlos - UFSCAR, Campus Sorocaba \\ mmartines@ufscar.br \\ Luiza Maria de Assunção \\ Universidade do Estado de Minas Gerais - UEMG, Unidade Ituiutaba \\ luiza.assuncao@uemg.br
}

\begin{abstract}
RESUMO
Uma das formas de monitorar o espalhamento do novo coronavírus é pela análise cartográfica de mapas temáticos sobre as notificações de casos confirmados de Covid-19 e outras variáveis geográficas. Este estudo mostra resultados do mapeamento de casos de COVID-19 na Macrorregião de Saúde Triângulo Sul, MG, relacionando dados geográficos para compreender a dinâmica espacial da doença nessa área. Os dados utilizados são provenientes das notificações fornecidas pela Superintendência Regional de Saúde de Uberaba, referentes aos 27 municípios sob sua jurisdição. São utilizados Sistemas de Informação Geográfica (SIG), planilhas eletrônicas e mapas base para a construção de banco de dados geoespacial e produção de mapas temáticos. Os resultados mostram que os primeiros casos ocorreram nas cidades com maior população e possuem maior conectividade com metrópoles e cidades médias, indicando uma possível correlação entre a hierarquia das cidades na rede urbana e a disseminação do vírus nas populações. $\mathrm{Na}$ escala intra-urbana, os casos se concentram na porção central das cidades e a maior taxa de infecção ocorreu em Uberaba, município de maior população e que centraliza a Macrorregional. O estudo prevê o acompanhamento da pandemia da COVID-19 e o subsídio à vigilância epidemiológica na região de saúde, com o mapeamento temático e apontamento de possíveis fatores de risco e da difusão espacial da doença.
\end{abstract}

PALAVRAS-CHAVE: Coronavírus. Sistemas de Informação Geográfica. região de saúde. epidemiologia.

\begin{abstract}
One of the ways to monitor new coronavirus spread is through cartographic analysis and thematic maps on notifications of Covid-19 positive cases and other geographic variables. This study shows results of positive COVID-19 cases mapped in Triângulo Sul Macroregion of Health in Minas Gerais, considering geographic data to understand spatial dynamics of the disease in this area. Data used come from the notifications provided by the Regional Health Superintendence of Uberaba, referring to the 27 municipalities under its jurisdiction. Geographic Information Systems (GIS), spreadsheets and base maps were used to build a
\end{abstract}

Recebido em: 01/05/2020

Aceito para publicação em: 26/05/2020. 
geospatial database and produce thematic maps. The results shows that the first cases occurred in cities with larger population and connectivity with metropolis and medium cities, indicating a possible correlation between city hieranchy in the urban network and dissemination of the virus in populations groups. At the intraurban scale, cases are concentrated nearby to down town and the highest infection rate occurred in the city of Uberaba, that have largest population and centralizes the Macroregional region. The study will follow COVID-19 pandemic and will help epidemiological surveillance in the health region, producing thematic maps and indicating possible geographical risk factors to the disease propagation in space.

KEYWORDS: Coronavirus. Geographic Information System. health region. Epidemiology.

\section{INTRODUÇÃO}

A Covid-19 é altamente transmissível, pois se dá por meio de gotículas de saliva, contato pessoal próximo e contato com superfícies contaminadas, seguidas de contato com a boca, nariz ou olhos. Os sintomas variam de leves, a maioria, mas algumas pessoas podem ser agravadas e outras virem a óbito. A rápida expansão mundial da doença em 2020 e os riscos de pressão do sistema de saúde têm levado a uma mobilização internacional para desacelerar o espalhamento da doença no tempo e no espaço. No Brasil, o primeiro caso confirmado data de 26 de fevereiro de 2020 . Em 30 de abril de 2020, foram confirmados 78.162 casos, 5.466 óbitos e uma taxa de letalidade de $7.0 \%$, sendo a Região Sudeste do país a mais afetada, com 49,8\% dos casos. Até então, a curva segue ascendente, com provável crescimento nas semanas que sucedem, figurando como uma das nações com as maiores taxas de contágio (BHATIA et al. 2020).

Com o rápido aumento de mortes é essencial considerar a distribuição espacial dos casos da Covid19 para apoio ao monitoramento epidemiológico e a tomada de decisão. O mapeamento, por meio da tecnologia SIG, permite executar o monitoramento espacial de forma mais eficiente, pois armazena, recupera, analisa e atualiza dados espaciais em banco de dados digitais. Assim, os casos relacionados à Covid-19 podem ser mapeados, bem como, as variáveis secundárias que possam ter relação com os riscos de seu espalhamento no território. Usando dados fornecidos pela Superintendência Regional de Saúde de Uberaba de Minas Gerais, provenientes de sistemas de informação de saúde oficiais (ESUS-VE e SIVEP-GRIPE), dados de saúde estão sendo mapeados no decorrer da pandemia mundial da doença do novo coronavírus (SARS-Cov2), tendo em vista o subsídio às ações da vigilância epidemiológica e produção de pesquisa sobre os aspectos geográficos da difusão espacial da doença.

\section{MAPEAMENTO DE DOENÇA DE ALTO CONTÁGIO}

O novo coronavírus tem processo de contágio semelhante às síndromes gripais, portanto, as metodologias de análise geográfica de risco e espalhamento da doença podem se balizar em estudos relacionados aos vírus da Influenza. Diversos estudos aplicam tais métodos (LAl; KWONG, 2008; ZHANG, et al. 2014; WANG, et al. 2010). O mapeamento de casos desagregados, ou seja, em nível pontual que oferece maior de detalhamento da difusão geográfica dos casos (LAl; KWONG, 2008; WANG, et al. 2010; PEREZ; DRAGICEVIC, 2009). Estudos que mapearam as síndromes respiratórias causadas pelo vírus influenza, revelaram que a aplicação de técnicas de visualização espacial de dados pontuais permite identificar agrupamentos e tendências de espalhamento. Isso auxilia a formulação de ações de controle em grupos populacionais específicos, orientando ações de isolamento social com base em casos suspeitos, confirmados e recuperados (LAl; KWONG, 2008).

Outra experiência exitosa ocorreu no estudo geográfico de Sars-Cov no surto de 2003 em Hong Kong (LAl et al., 2004). Com uso de SIG, mapearam por meio de endereços residenciais 1.709 casos confirmados de SRAG. Os métodos utilizados se basearam em modelos de análise espacial sobre pontos e geração de superfície estatística, que destaca a variação espacial das ocorrências. Analisaram a evolução do espalhamento no decorrer de 16 semanas, com isso, puderam caracterizar os locais e a duração do pródromo da epidemia, bem como, a evolução regional. Concluíram que os métodos SIG são úteis durante um surto de doença de alto contágio, pois possibilitam o acréscimo DOl:http://dx.doi.org/10.14393/Hygeia0054379 $\quad$ Hygeia $\quad$ Edição Especial: Covid-19, Jun./2020 $\quad$ p.49 - 59, $\quad$ pág. 50 
das informações geoespaciais, avançando nas análises epidemiológicas padrão. Atestaram ainda, que o mapeamento de doenças é o primeiro passo para entender aspectos espaciais de problemas relacionados a saúde. Contudo, ressaltaram que existem limitações nas técnicas SIG, quando mostram apenas o "onde" e não o "porquê" da localização do surto, mas servem como bases para as formulações de hipóteses e orientação de ações localizadas (LAl et al., 2004).

O espalhamento da Covid-19 tem características geográficas que, por meio da análise da distribuição espacial de casos suspeitos, confirmados e recuperados, bem como, a observação de variáveis complementares, como as demográficas, uso da terra, limites territoriais, entre outros, permitem a compreensão de sua dinâmica no espaço. A análise cartográfica é fortemente dependente da escala de representação.

Para o monitoramento de doenças, a análise mais detalhada ocorre no nível do endereço residencial, reduzindo-se para a escala do bairro, município, região, estado e nacional. Uma abordagem multiescalar foi desenvolvida na China para o acompanhamento da epidemia do novo coronavírus. Com uso da tecnologia SIG, a Academia Chinesa de Tecnologia da Informação e Comunicações construiu um sistema de informação Big Data para acompanhar, em tempo real, as notificações em múltiplos sistemas dos dados da Covid-19 em todo o território chinês, gerando visualizações dinâmicas de mapas temáticos em diferentes escalas temporais e espaciais, desde províncias, cidade, comunidade e indivíduo (ZHOU, et. al. 2020). Com esta aplicação conseguiram executar três análises, em três níveis escalares distintos. $\mathrm{Na}$ escala do indivíduo, rastrearam a trajetória dos pacientes e da epidemia no tempo e espaço. Na escala dos grupos populacionais, estimaram o fluxo populacional e a distribuição da doença. $\mathrm{Na}$ escala regional, definiram espaços de risco e de desequilíbrio entre a oferta e demanda de recursos de saúde.

\section{MATERIAIS E MÉTODOS}

A disponibilidade e organização de dados é fundamental nas ações de vigilância em saúde como prevenção e controle. Na Região Triângulo Sul (MG), o fluxo de informações para mapeamento processa-se a partir de 2 principais sistemas de informação de saúde: [1] Sistema de Informação da Vigilância Epidemiológica da Gripe (SIVEP Gripe); [2] e-SUS VE, que é uma ferramenta de registro de notificação de casos suspeitos e confirmados de Síndrome Gripal com referência ao Novo Coronavírus - COVID-19; e uma planilha de notificações de casos confirmados e óbitos de COVID-19 da Superintendência Regional de Saúde (SRS) de Uberaba. Cada uma destas fontes reportam os casos de forma diferente quanto ao fluxo temporal e o detalhamento de dados. O maior fluxo temporal de informação vem pela planilha do SRS, mas seu detalhamento é menor. As planilhas geradas pelos sistemas SIVEP Gripe e e-SUS VE tem maior detalhamento de dados do paciente, porém o fluxo de atualização varia de município para município (Tabela 1).

Neste estudo utiliza-se a base territorial do IBGE (2010) para a delimitação dos limites das Unidade da Federação (UF), representação dos limites dos municípios e dos subdistritos/bairros urbanos dos municípios de Uberaba e Araxá como unidade espacial de análise. Os bairros constantes na base IBGE de Araxá foram vetorizados com base no mapa do Plano Diretor Estratégico de Araxá, disponibilizado pela prefeitura municipal de Araxá. Os bairros do município de Frutal foram extraídos do Wikimapia, que é uma plataforma de mapeamento colaborativo independente (https://wikimapia.org/).

Os endereços constantes nas planilhas de notificação foram mapeados em pontos, com uso de técnica de geocodificação de endereços no software Google Earth. Os endereços não identificados pelo método automático são georreferenciados por consulta a mapas base, como Google maps, Esri Streets e Open street map.

Outras bases de dados temáticas foram integradas no estudo e servem como informações auxiliares para a interpretação e análise das visualizações cartográficas, tais como: população absoluta, densidade demográfica, vias de circulação e redes de influência, imagem de satélite. Os softwares utilizados são ArcMap e QGIS. As planilhas foram consultadas diariamente e casos suspeitos (síndromes gripais e casos de síndrome respiratória aguda grave) e confirmados formam mapeados em camadas temáticas e publicados com frequência semanal, ou em edições extraordinárias, para a composição dos Boletins Epidemiológicos da SRS de Uberaba. 
Tabela 1 - Bases de notificações e campos descritivos

\begin{tabular}{|c|c|}
\hline Base de dados & Campos descritivos \\
\hline SRS & $\begin{array}{l}\text { Código e-SUS ou SIVEP Gripe (quando houver); Nome; Paciente; } \\
\text { Sexo; Idade; Data de nascimento; Município de residência; URS } \\
\text { (Unidade Regional de Saúde); Data de recebimento da informação; } \\
\text { Laboratório que liberou exame; Internação (SIM ou NÃO); } \\
\text { Internação em CTI (SIM ou NÃO); Data de internação; Unidade de } \\
\text { saúde de internação; Evolução (recuperado, alta ou óbito); Data de } \\
\text { evolução; Comorbidade (descrição); Endereço (Rua, número, } \\
\text { complemento); Bairro }\end{array}$ \\
\hline e-SUS VE & $\begin{array}{l}\text { Número da Notificação Data da Notificação; CPF; Nome } \\
\text { Completo; Classificação Final; } \quad \text { Data de Nascimento; Raça/Cor; } \\
\text { Sexo; Nome Completo da Mãe; É profissional de saúde?; CBO; } \\
\text { Passaporte; Pais de origem; Estrangeiro; Estado de Residência; } \\
\text { Município de Residência; Data de coleta do teste; Estado do Teste; } \\
\text { Tipo de Teste; Resultado do Teste; Data da Coleta do Teste; Estado } \\
\text { do Teste; Tipo de Teste; Resultado do Teste; Evolução Caso; Data } \\
\text { de encerramento; Operador CNES; Operador CPF; Operador } \\
\text { Email; Operador Nome Completo }\end{array}$ \\
\hline SIVEP Gripe* & $\begin{array}{l}\text { Data do preenchimento da ficha de notificação; Data de } 1^{\circ} \text { S } \\
\text { sintomas; UF; Município; Código IBGE; Unidade de Saúde; Código } \\
\text { (CNES); Dados do Paciente (CPF, Nome, Sexo, Data de } \\
\text { Nascimento, Idade, Gestante (tempo), Etnia, Escolaridade, } \\
\text { Ocupação, Nome da mãe); Dados de Residência (UF, Município, } \\
\text { Código IBGE, Bairro, Logradouro, número, Complemento, telefone); } \\
\text { Dados clínicos e epidemiológicos (histórico de viagem com } \\
\text { detalhamento; se trata-se de caso proveniente de surto de SG que } \\
\text { evoluiu para SRAG, se trata-se de infecção adquirida no hospital, } \\
\text { se o paciente trabalha ou tem contato direto com aves ou suínos, } \\
\text { sinais e sintomas, fatores de risco/comorbidades, se recebeu } \\
\text { vacina contra a gripe na última campanha); dados de atendimento } \\
\text { (se usou antiviral e qual, se houve internação (com detalhes de } \\
\text { onde e quando), se internado em UTI (com de talhes de onde e } \\
\text { quando), se usou suporte ventilatório); dados laboratoriais } \\
\text { (resultado, data, método do teste, laboratório que realizou, } \\
\text { resultado da RT-PCR ou outro método; Conclusão (classificação } \\
\text { final do casos (se: SRAG influenza, SRAG por outro vírus } \\
\text { respiratório, SRAG por outro agente etiológico e qual, SRAG não } \\
\text { especificado ou COVID-19), critério de encerramento, evolução do } \\
\text { caso, data da alta ou óbito, data de encerramento; observações; } \\
\text { profissional responsável. }\end{array}$ \\
\hline
\end{tabular}

Foram produzidos mapas temáticos da região, com os 27 municípios da Macrorregião, representados pelo método coroplético dos casos absolutos de Covid-19. Os mapas de pontos foram produzidos para os municípios que centralizam os serviços de saúde em cada mesorregião, a saber: Uberaba, Araxá e Frutal. Para estes municípios, são produzidos mapas de pontos com a localização dos casos na área urbana com sobreposição de polígonos dos bairros.

\section{CARACTERIZAÇÃO DA ÁREA ESTUDADA}

A macrorregião de saúde Triângulo Sul coincide com a Região Geográfica Intermediária definida pelo IBGE (2017). Integra 27 municípios que se subdividem em três Mesorregiões de Saúde: Araxá, Uberaba e Frutal (figura 1). A área possui uma grande extensão longitudinal, as duas sedes municipais extremas, Carneirinho (a oeste) e Campos Altos (à leste), distam $530 \mathrm{~km}$ entre si, isso denota a importância das definições de Mesorregiões para o atendimento dos municípios do entorno. 
Figura1 - Macrorregião de Saúde Triângulo Sul (MG)

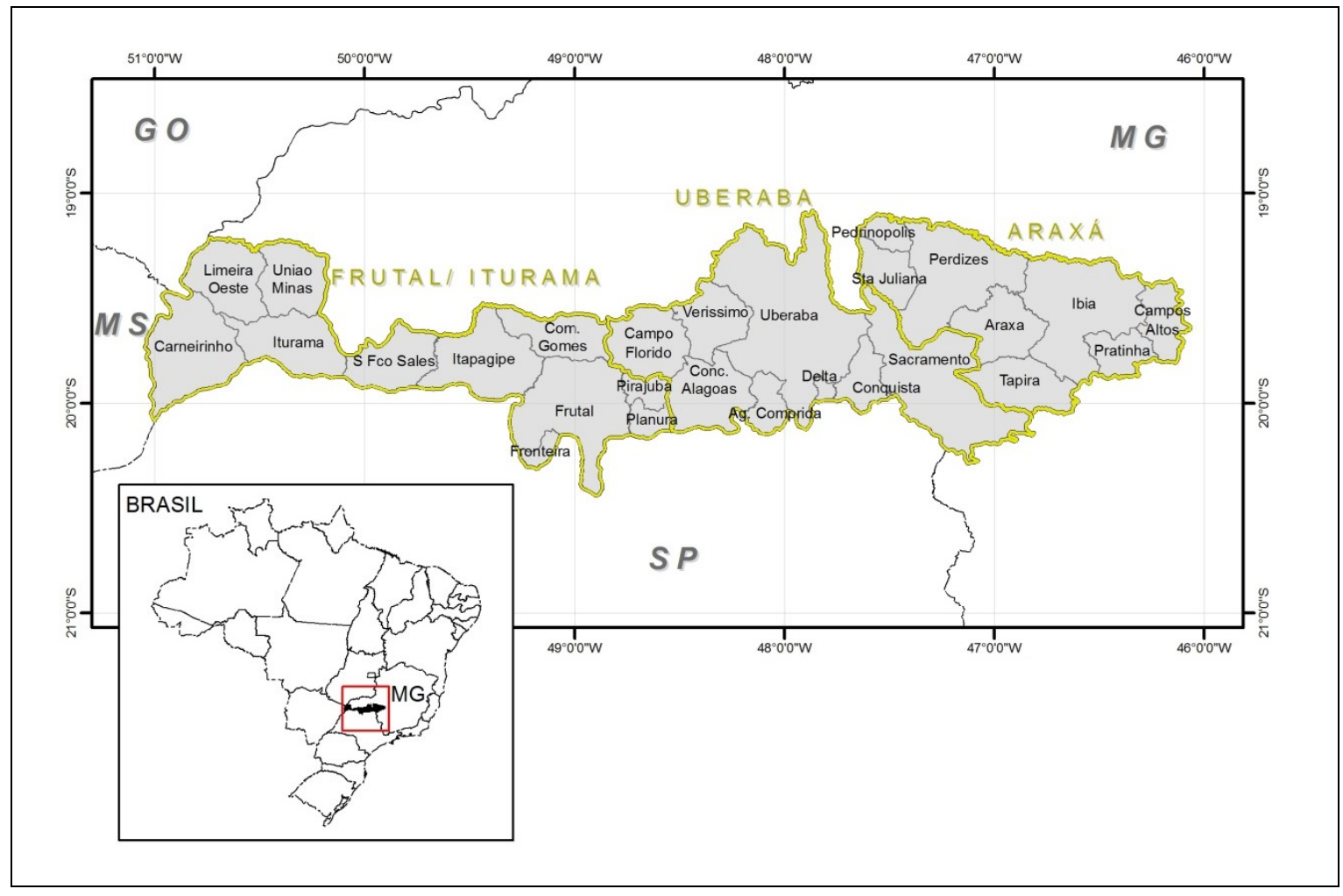

Segundo dados do IBGE Cidades (2020), a população estimada para a região, em 2019, é de 790.206 habitantes. A cidade de Uberaba, com população estimada em 333.783 em 2019 (IBGE), centraliza a região e detém os serviços de saúde de maior complexidade, tanto em tecnologia, quanto de profissionais. Seguido por Araxá, com população estimada em 106.229 habitantes, Frutal, com 59.469 habitantes, e Iturama com 39.263 habitantes (figura2).

Figura 2 - População absoluta dos municípios da Macrorregião do Triângulo Sul (MG)

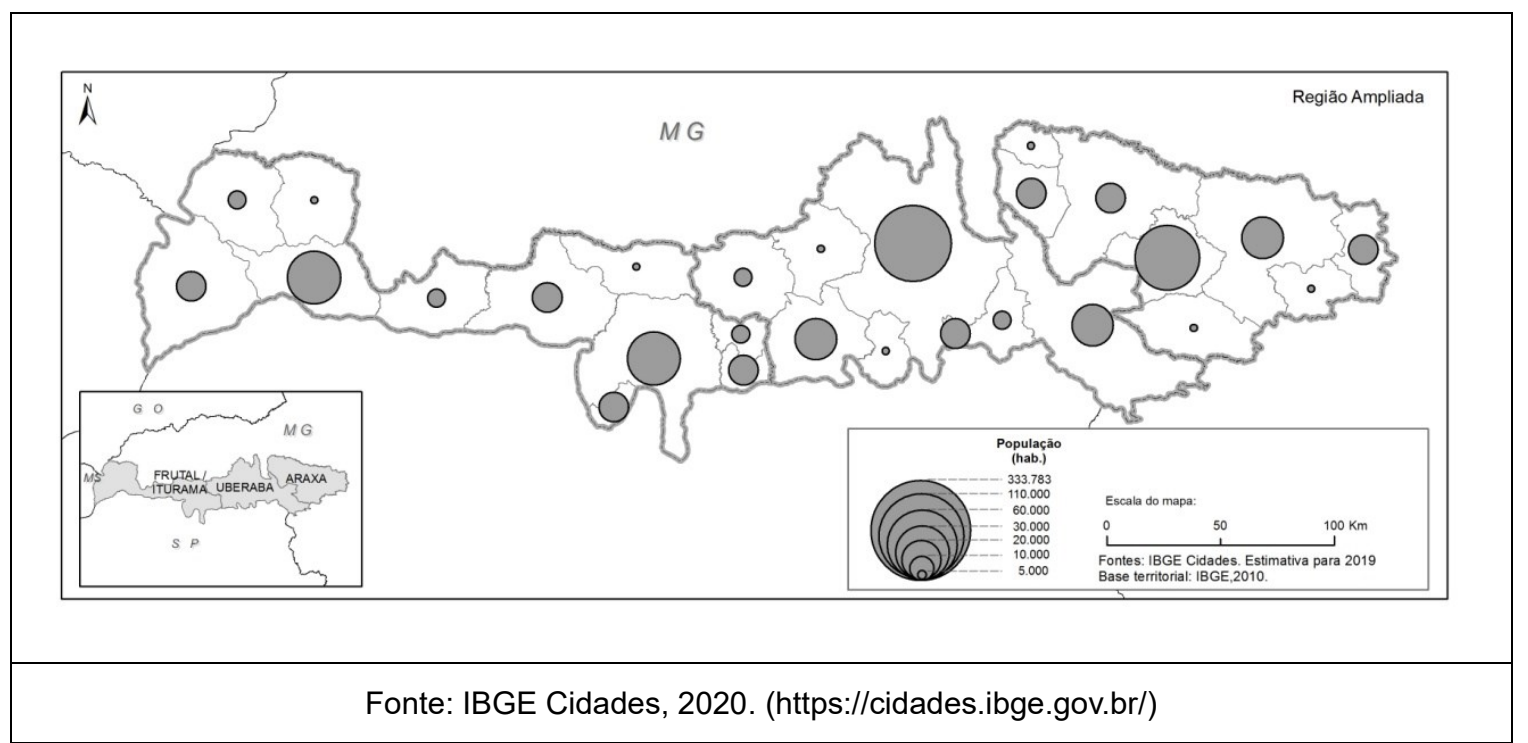


Os municípios da região possuem diferentes vínculos, que podem ser observados na classificação das Regiões de Influência das Cidades - REGIC (IBGE, 2018). Tais influências destacam as relações de bens, serviços e atividades de gestão de um município com outro(s) município(s). Geralmente estas vinculações são constatadas entre mais de um município e não são, necessariamente, compartilhadas com centros de uma mesma região. No Triângulo Sul (MG) o município de São José do Rio Preto (SP) mantém forte vínculo com os municípios da Mesorregião de Frutal/lturama e Belo Horizonte com Uberaba, Frutal e Iturama. No contexto regional, Araxá está mais vinculado com Uberaba (figura 3).

Figura 3 - Redes Finais de Regiões de Influência das Cidades (REGIC) do Triângulo Sul

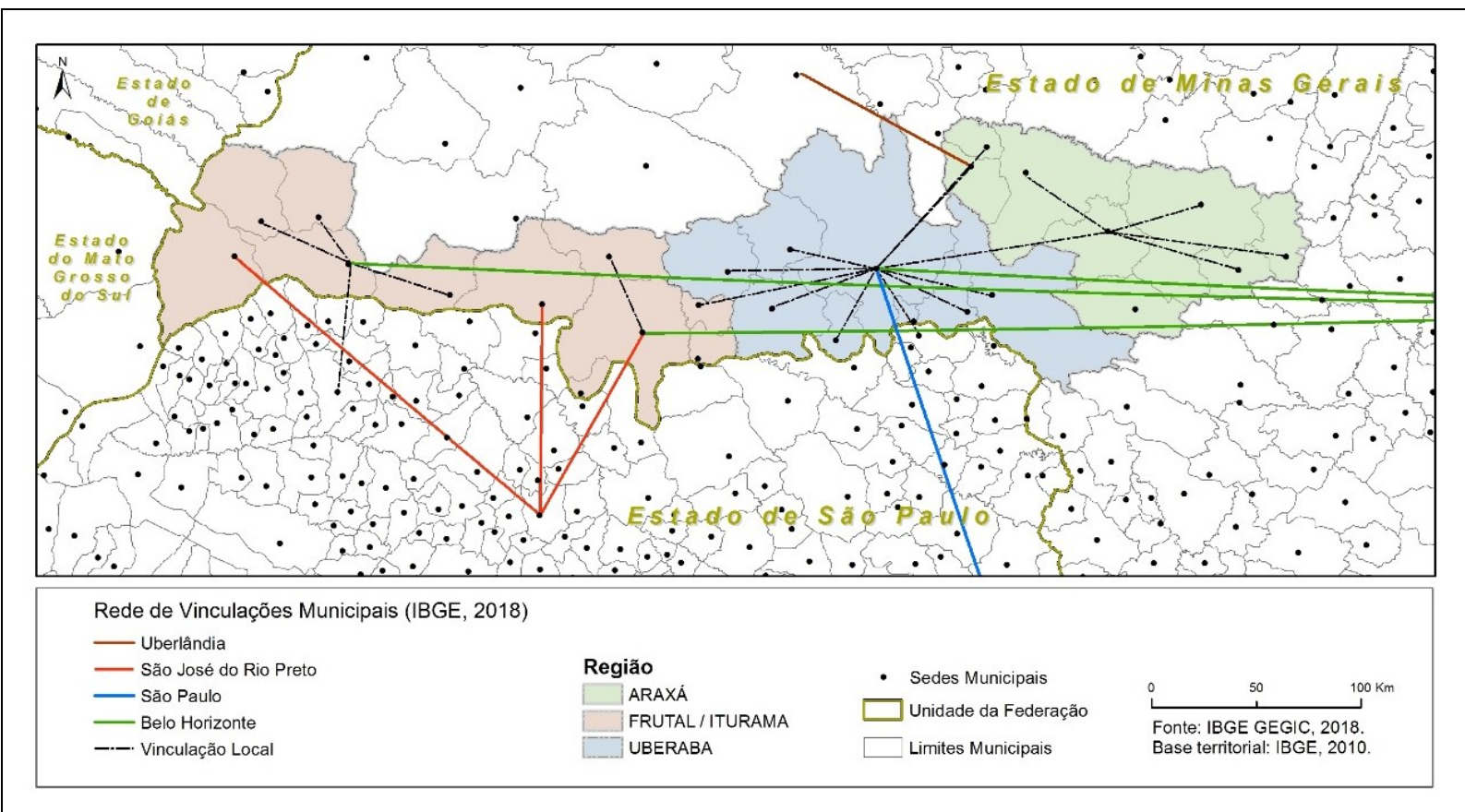

\section{RESULTADOS DO MAPEAMENTO DE CASOS SUSPEITOS E CONFIRMADOS DE COVID-19 NA MACRORREGIÂO DO TRIÂNGULO SUL (MG)}

O primeiro caso de coronavírus na macrorregião do Triângulo Sul (MG) data de 23 de março de 2020, e ocorreu no município de Campos Altos. Na quinta semana da epidemia na região, foram contabilizados 60 casos confirmados, com epicentro no município de Uberaba (figura 4). O aumento das notificações nos demais municípios coincide com a terceira semana epidemiológica na região, com curva ascendente no município de Uberaba e estabilização nas demais cidades (Figura 4).

A taxa de infecção considerada para o período de 1 (um) mês é de $6.9 \%$. Até a data de 25 de abril de 2020, contabilizou-se 3 óbitos, todos ocorridos no município de Uberaba, representando um coeficiente de letalidade de $5 \%$ para a região, tendo por base os casos notificados.

A distribuição espacial das infecções ocorre nas cidades com maior população, com exceção do município de Campos Altos, que não registrou novos casos desde a notificação do primeiro caso, detectada como infecção alóctone (figura 5). 
Covid-19 na região de saúde Triângulo Sul, MG: uma perspectiva cartográfica

Ricardo Vicente Ferreira

Denise Maciel Carvalho Ana Laura de Paula Souza Marcos Roberto Martines Luiza Maria de Assunção

Figura 4 - Evolução dos casos positivos de Covid-19 na Macrorregião do Triângulo Sul (MG) até a quinta semana a partir do primeiro caso notificado

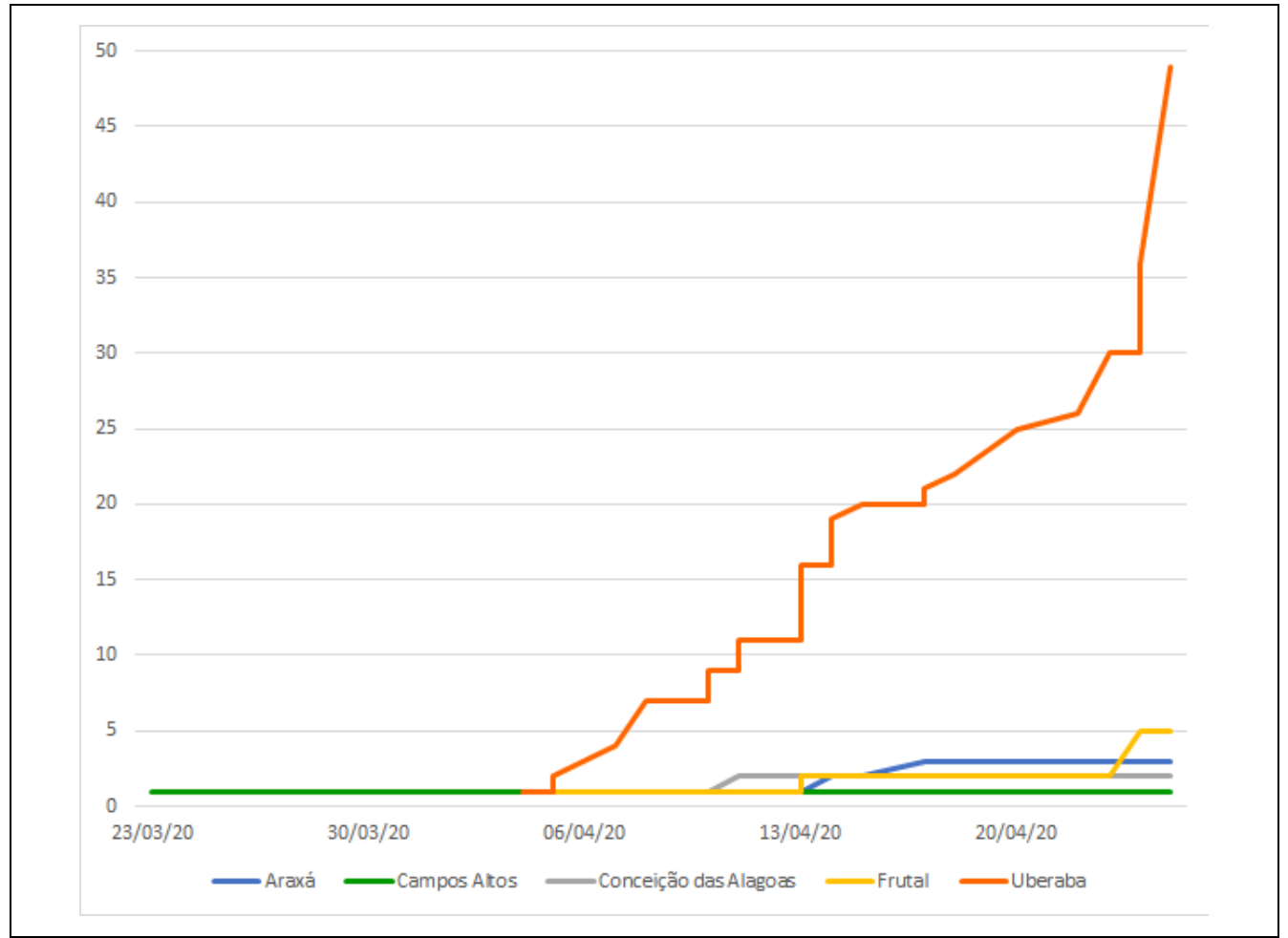

Figura 5 - Totais de casos de Covid-19 por município da Macrorregião do Triângulo Sul (MG) em 26 de abril de 2020

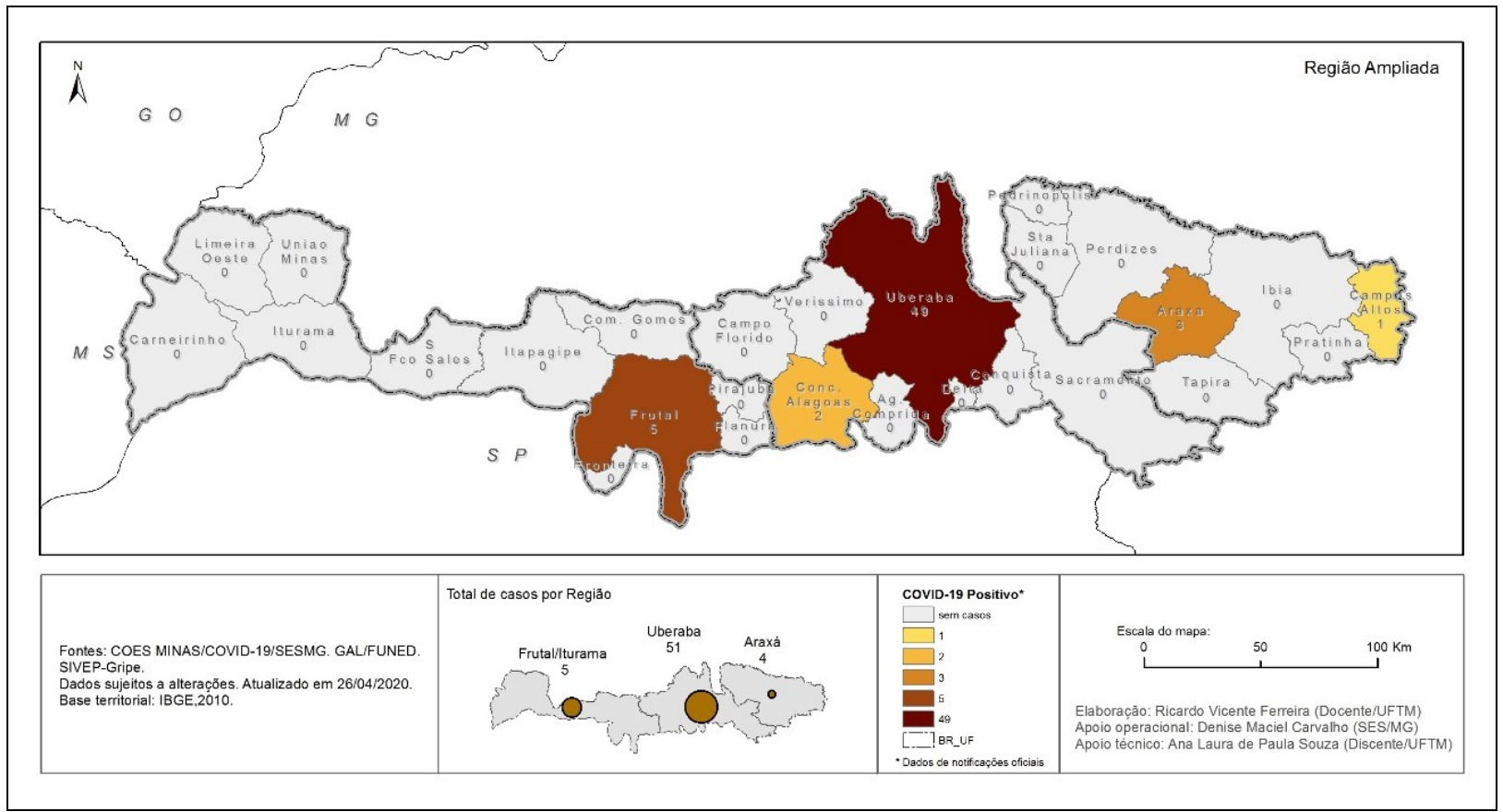


As representações cartográficas em escala intra-urbana, são produzidas para os municípios centrais de cada mesorregião. As Síndromes Gripais (SG) e Síndromes Respiratórias Agudas Graves (SRAG) são notificadas como casos suspeitos de coronavírus. A distribuição destas notificações são dispersas e em maior ocorrência no espaço intra-urbano, contudo, as primeiras confirmações de COVID-19 tendem a ocorrer próximo ao centro urbano. É possível inferir que existe uma dinâmica em função da influência das redes urbanas e dos fluxos, onde a partir desse arranjo, observa-se a cidade de Uberaba com maiores casos e as cidades ligadas a ela em cidades dos níveis inferiores com menores casos (Figuras 6, 7, 8).

Os casos de Covid-19 em Frutal se localizam próximos ao centro urbano, com 3 casos posicionados em uma mesma localidade.

Figura 6 - Distribuição espacial de casos de Covid-19 e síndromes gripais em Frutal (MG)

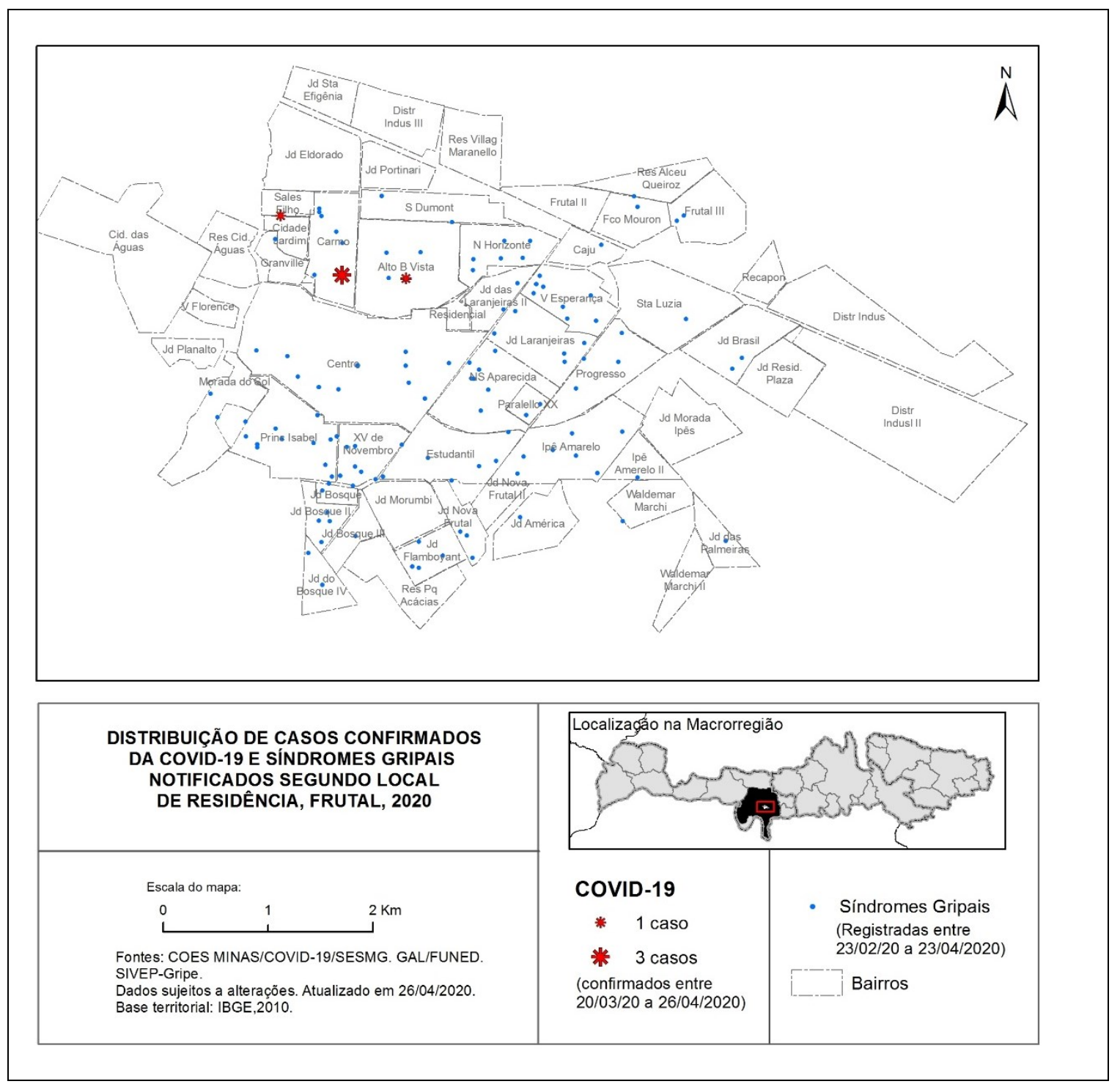


A distribuição dos casos confirmados em Araxá também se concentra na região central, mas devido às poucas ocorrências tanto em Frutal, quanto em Araxá, não se pode inferir sobre a tendência da distribuição espacial dos mesmos (Figura 7).

Figura 7 - Distribuição espacial de casos de Covid-19 e síndromes gripais em Araxá (MG)

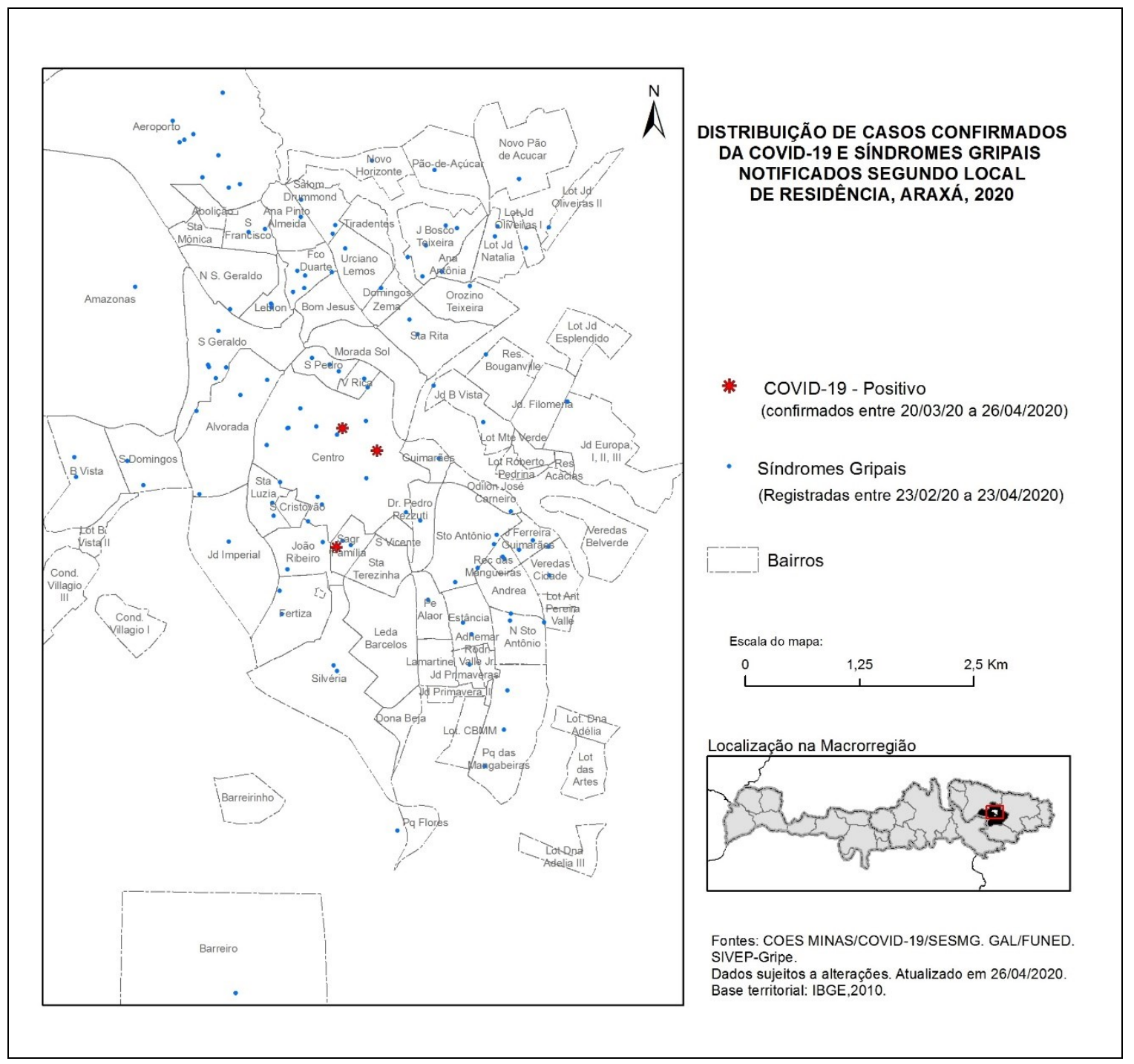

A ocorrência de casos confirmados em Uberaba denota maior frequência na região central, mas as notificações mais recentes se localizam nas áreas periféricas à mancha urbana, isto é, em bairros como Recreio do Bandeirantes, Fabrício e Grande Horizonte (Figura 8). 
Figura 8. Distribuição espacial de casos de Covid-19 e síndromes gripais em Uberaba (MG)

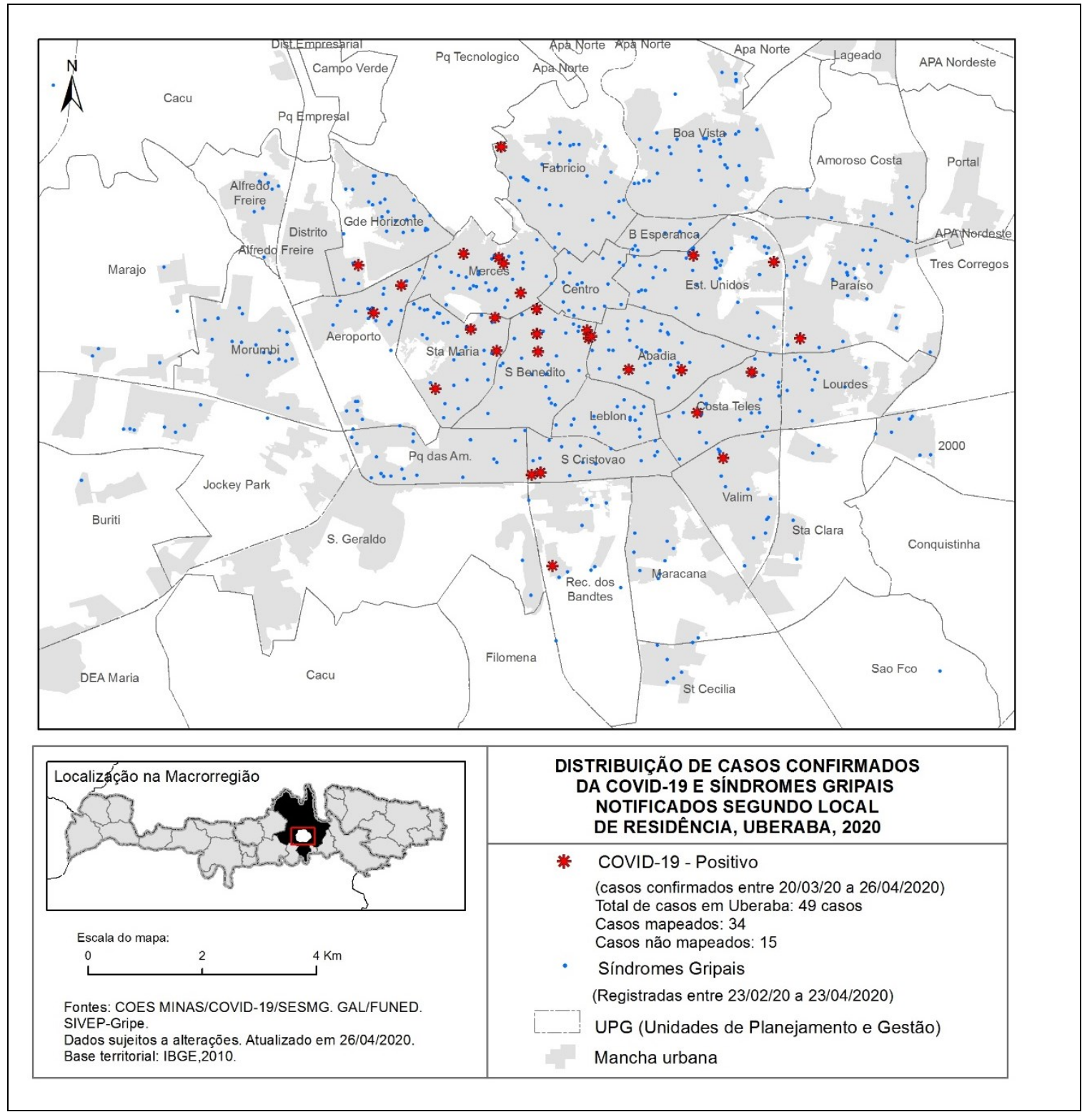

\section{CONSIDERAÇÕES FINAIS}

A ocorrência de casos notificados até o dia 26 de abril de 2020 denota que a sua distribuição espacial tem relacão com municípios de maior quantitativo populacional que, por sua vez, estabelecem maiores vínculos com metrópoles e cidades médias que são externas à região. Isso leva à hipótese de que, em eventos futuros, as fontes alóctones de infecção possam advir destes locais. A pandemia do novo coronavírus segue um caminho ainda incerto quanto a sua evolução no tempo e no espaço e as possibilidades de pressão no sistema de saúde são factíveis, podendo resultar em limitações de vagas para internação e escassez de equipamentos de ventilação mecânica. Tomando como referência o pacto pela saúde, que institui a gestão da saúde com base no planejamento regional, os pacientes dos municípios integrantes da Macrorregião Triângulo Sul buscarão por atendimento nos municípios com maior capacidade de saúde (BRASIL, 2006), independentemente dos vínculos com municípios externos à região (Referenciar!).

O mapeamento das notificações de Sídrome Gripal (SG) e Síndrome Respiratória Aguda Grave 
(SRAG) torna-se instrumento fundamental no apoio ao acompanhamento da difusão espacial do Coronavírus (Covid-19). O projeto justifica-se no fato de não haver na Macrorregião de Saúde Triângulo Sul (MG) prestação de apoio técnico em geoprocessamento aos órgãos de Vigilância em Saúde para o monitoramento da pandemia. Os resultados são compartilhados e discutidos semanalmente com os responsáveis pela vigilância epidemiológica da Superintendência Regional de Saúde de Uberaba.

\section{AGRADECIMENTOS}

Esse trabalho tem o apoio da Superintendência Regional de Saúde de Uberaba no fornecimento de dados para mapeamento e da Fundação de Ensino e Pesquisa de Uberaba - FUNEPU na concessão de bolsa extensão universitária para o enfrentamento da emergência de saúde pública decorrente do Coronavírus (COVID-19).

\section{REFERENCIAS BIBLIOGRÁFICAS}

BATHIA, S.; CORI, A.; PARAG, K. V. et al. Short-term forecasts of COVID-19 deaths in mulltiple coutries. Imperial College London. Imperial College COVID-19 response team, 2020. Disponível em: <https://mrc-ide.github.io/covid19-short-term-forecasts/index.html\#authors>. Acesso em 30 de abr de 2020.

BRASIL. Portaria GM/MS n. ${ }^{\circ}$ 399, de 22 de fevereiro de 2006. Divulga o Pacto pela Saúde 2006 Consolidação do SUS e aprova as Diretrizes Operacionais do Referido Pacto. Diário Oficial da União, Brasília, DF, 23 fev. 2006. Disponível em: < https://www.saude.mg.gov.br/fornecimento-demedicamentos/page/69-pacto-pela-saude-sesmg>. Acesso em: 22 mai. 2020.

IBGE. Instituto Brasileiro de Geografia e Estatística (IBGE). Cidades. 2017. Disponível em: <https://cidades.ibge.gov.br/>. Acesso em: 30 abr. 2020.

LAI PC, WONG CM, HEDLEY AJ, LO SV, LEUNG PY, KONG J, LEUNG GM. Understanding the spatial clustering of severe acute respiratory syndrome (SARS) in Hong Kong. Environmental Health Perspectives. 2004 Nov;112(15):1550-6. doi: 10.1289/ehp.7117. https://doi.org/10.1289/ehp.7117

LAI, PC; KWONG, K. Spatial Analysis of the 2008 Influenza Outbreak of Hong Kong. In: Taniar, D. et al. (Hrsg): Computational Science and Its Applications - Iccsa 2010. International Conference, Fuluoka, Japan, Março 23-26, Proceedings, Part I. Springer, Berlin/Heidelberg. https://doi.org/10.1007/978-3-642-12156-2_29

PEREZ, L; DRAGICEVIC, S. An agent-based approach for modeling dynamics of contagious disease spread. International Journal of Health Geographics 2009, 8:50. https://doi.org/10.1186/1476$\underline{072 X-8-50}$

WANG, J; XIONG, J; YANG, K; PENG, S; XU, Q. Use of GIS and Agent-Based Modeling to Simulate the Spread of Influenza. 2010 18th International Conference on Geoinformatics. Beijing, China. 10.1109/GEOINFORMATICS.2010.5567658. https://doi.org/10.1109/GEOINFORMATICS.2010.5567658

ZHANG, J C; LIU, W; LIANG, Q; HU, J; NORRIS, J; WU, Y; BAO, C; TANG, F; HUANG, P; ZHAO, Y; YU, R; ZHOU, M; SHEN, H; CHEN, F; PENG, Z. Spatial distribution and risk factors of influenza in Jiangsu province, China, based on geographical information system. Geospatial Health 8(2), 2014, pp. 429-435. https://doi.org/10.4081/gh.2014.31

ZHOU, C.; SU, F Su; PEI, T. et al. COVID-19: Challenges to GIS with Big Data, Geography and Sustainability, https: //doi.org/10.1016/j.geosus.2020.03.005 